\title{
Partial Mastectomy Reconstruction with Local and Distant Tissue Flaps
}

\author{
Stefan Krämer ${ }^{\mathrm{a}}$ Sherko Kümmel ${ }^{\mathrm{b}} \quad$ Oumar Camara $^{\mathrm{c}} \quad$ Regina Große $^{\mathrm{d}} \quad$ Michael Friedrich $^{\mathrm{e}}$ \\ Jens-Uwe Blohmer \\ a Brustzentrum Düsseldorf, Luisenkrankenhaus, \\ ${ }^{b}$ Frauenklinik, Universitätsklinikum Essen, \\ c Frauenklinik, Universitätsklinikum Jena, \\ ${ }^{\mathrm{d} F r a u e n k l i n i k, ~ U n i v e r s i t a ̈ t s k l i n i k u m ~ H a l l e, ~}$ \\ ${ }^{e}$ Frauenklinik, Klinikum Krefeld, \\ ${ }^{f}$ Abt. Gynäkologie und Geburtshilfe, St. Gertrauden Krankenhaus, Berlin, Germany
}

\section{Key Words}

Oncoplastic surgery · Breast surgery - Breast-conserving therapy · Breast cancer - Breast reconstruction

\section{Summary}

Breast-conserving surgery combined with radiotherapy has become the treatment of choice for the majority of women presenting with primary breast cancer over the last 20 years. The extent of local excision remains a controversial issue in breast-conserving surgery. The wider the margins of clearance, the less the risk of incomplete excision and thus of local recurrences, but the greater the amount of tissue removed, the higher the risk of visible deformity leading to an unacceptable cosmetic result. This clash of interests is most evident when attempting breast-conserving surgery in patients with smaller breast/ tumor ratios. The widespread popularity of breast-conserving surgery has focused attention on new oncoplastic techniques that can avoid unacceptable cosmetic results. Partial mastectomy defects can be reconstructed by volume displacement (recruiting and transposing local glandular or dermoglandular flaps into the resection site), or by volume replacement techniques. There is a wide spectrum of oncoplastic techniques which have been published during the last years necessitating a systematic structuring of these procedures in terms of indication, outcome, and technical details.

\section{Schlüsselwörter \\ Onkoplastische Chirurgie - Mammachirurgie . Brusterhaltende Therapie - Mammakarzinom . Brustrekonstruktion}

\section{Zusammenfassung}

Die brusterhaltende Therapie hat sich in den letzten 20 Jahren zur Behandlungsmethode der Wahl bei den meisten Patientinnen mit Mammakarzinom entwickelt. Die Bedeutung der Ausdehnung des tumorfreien Resektionsrandes gehört allerdings heute immer noch zu den kontrovers diskutierten Aspekten im Zusammenhang mit der brusterhaltenden Operation. Je weiter der tumorfreie Resektionsrand, desto geringer wird das Risiko für inkomplette Resektion und Lokalrezidive. Andererseits nimmt das Risiko für sichtbare Deformitäten und inakzeptable kosmetische Ergebnisse mit zunehmendem Resektionsvolumen zu. Dieser Konflikt zwischen onkologischer Sicherheit und ästhetischem Resultat wird besonders bei kleiner Brust-Tumor-Ratio klinisch evident. Mit zunehmendem Einsatz der brusterhaltenden Therapie nimmt die Bedeutung für onkoplastische Operationsverfahren zur Vermeidung ungünstiger kosmetischer Operationsergebnisse zu. Partielle Mastektomieverfahren können primär durch lokale Volumenverschiebung (glanduläre und dermoglanduläre Lappenbildung) oder durch Volumenersatztechniken rekonstruiert werden. Das teilweise unübersichtliche Spektrum publizierter onkoplastischer Operationsverfahren macht eine systematische Strukturierung in Bezug auf Indikationsstellung, Ergebnisse und technische Details notwendig.

\begin{tabular}{ll}
\hline KARGER & @ 2007 S. Karger GmbH, Freiburg \\
Fax +49 76145207 14 & Accessible online at: \\
$\begin{array}{l}\text { E-mail Information@Karger.de } \\
\text { www.karger.com }\end{array}$ & www.karger.com/brc
\end{tabular}




\section{Breast-Conserving Surgery - Histological and Biological Considerations}

The local treatment of breast cancer has changed dramatically in the last 100 years, reflecting changes in our understanding of the biology of breast cancer and improvements in diagnostic and therapeutic modalities [1-5]. The recognition that more extensive surgical procedures did not reduce the risk of distant metastases, coupled with the increasingly frequent identification of small breast cancers by mammography and the success of moderate-dose radiotherapy in eliminating subclinical foci of breast cancer, lead to trials of breast-conserving therapy [2, 3, 6-9]. The initial objection to breast-conserving therapy was based on the known multicentricity of breast carcinoma. The reported incidence of multicentricity ranged from 9 to $75 \%$, depending on the definition used, the extent of tissue sampling, and the techniques of pathologic examination [10]. The presence of multicentric tumor foci was used to argue against anything less than complete mastectomy as optimal local treatment for breast cancer.

The work of Holland et al. [10] provided a detailed description of the extent and distribution of cancer in a breast with an apparently localized tumor. In their initial report, mastectomy specimens with primary tumors of $4 \mathrm{~cm}$ or less in size were studied. In all cases, the tumors were considered unicentric based on clinical and radiographic assessment. Detailed evaluation of the breast was carried out using $5-\mathrm{mm}$ sections, radiography of these thin slices, and an average of 20 blocks per specimen for histological evaluation. This technique allowed precise mapping of the extent and distribution of residual carcinoma in relation to the primary (or reference) tumor. Only $39 \%$ of specimens showed no evidence of cancer beyond the reference tumor. In $20 \%$, additional cancer was found, but it was confined to within $2 \mathrm{~cm}$ of the reference tumor. $41 \%$ of patients had residual cancer more than 2 $\mathrm{cm}$ from the reference tumor; of those, two-thirds had pure intraductal carcinoma, and one-third had mixed intraductal and invasive carcinoma. The percentage of patients with residual cancer more than $2 \mathrm{~cm}$ from the reference tumor corresponds well to the rate of local failure reported in patients treated with excision of the primary tumor alone. In these series, local recurrence in the breast occurs at or near the site of the primary tumor in most cases, emphasizing that multifocal breast cancer commonly remains after an excision of the tumor, and that this multifocal involvement is biologically important. This is true even if the margins of surgical resection are assessed to be negative. However, radiotherapy is effective in controlling the majority of these occult foci of carcinoma [8]. The importance of these microscopic foci of tumor in the patient treated with excision and radiotherapy has again become an issue of clinical significance with the development of imaging modalities, such as magnetic resonance imaging (MRI) and ultrasound, which allow preoperative detection of very small foci of cancer [11].
Table 1. Systematic overview of volume displacement and volume replacement techniques (according to M. Rezai)

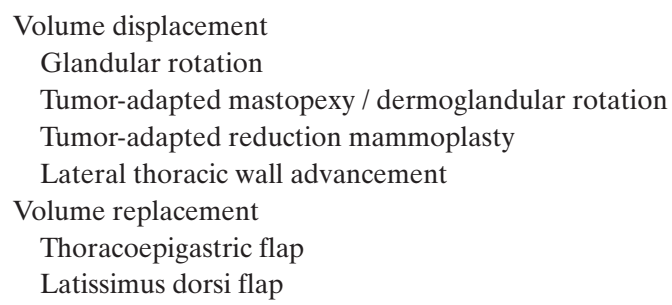

\section{Oncoplastic Breast-Conserving Surgery}

Breast-conserving therapy, consisting of lumpectomy or segmentectomy followed by radiotherapy, has become the standard form of treatment for invasive breast cancer and is increasingly being used for ductal carcinoma in situ (DCIS) and larger tumors $[2,3,12,13]$. However, with breast-conserving surgery for large tumors, there can be difficulty in obtaining clear excision margins, and the cosmetic outcome is often poor [14]. The tumor size in relation to the breast size is one of the most important factors when attempting to obtain a cosmetically favorable result. A conflict exists, therefore, between performing a resection wide enough to obtain optimal oncologic control and not removing so much breast tissue as to leave a deformed breast or a large discrepancy compared with the other side. One way of resolving this conflict is to use reconstructive procedures to reshape the breast immediately following partial mastectomy. This surgical approach, referred to as 'oncoplastic surgery', has rapidly gained acceptance in Europe and is now widely practiced in some dedicated breast units [15-18]. During the last years, a wide spectrum of different surgical techniques has been published, and it is therefore necessary to give an overview of these procedures based on a systematic structure in terms of indication, outcome, and technical details.

\section{Principles and Systematics of Partial Mastectomy Reconstruction}

The interrelationship between breast/tumor ratio, volume loss, cosmetic outcome, and margins of clearance is complex, and the widespread popularity of breast-conserving surgery has focused attention on new oncoplastic techniques that can avoid unacceptable cosmetic results. Until now, surgical options have been limited to breast-conserving surgery or mastectomy, the choice depending on fairly well-defined indications and factors. Oncoplastic procedures provide a third option that avoids the need for mastectomy in selected patients and can influence the outcome of breast-conserving surgery in 3 ways $[16,20,21]$. Oncoplastic procedures allow wide local excisions of breast tissue without risking major local defects 
Fig. 1. Surgical principle of segmental resection (partial mastectomy).
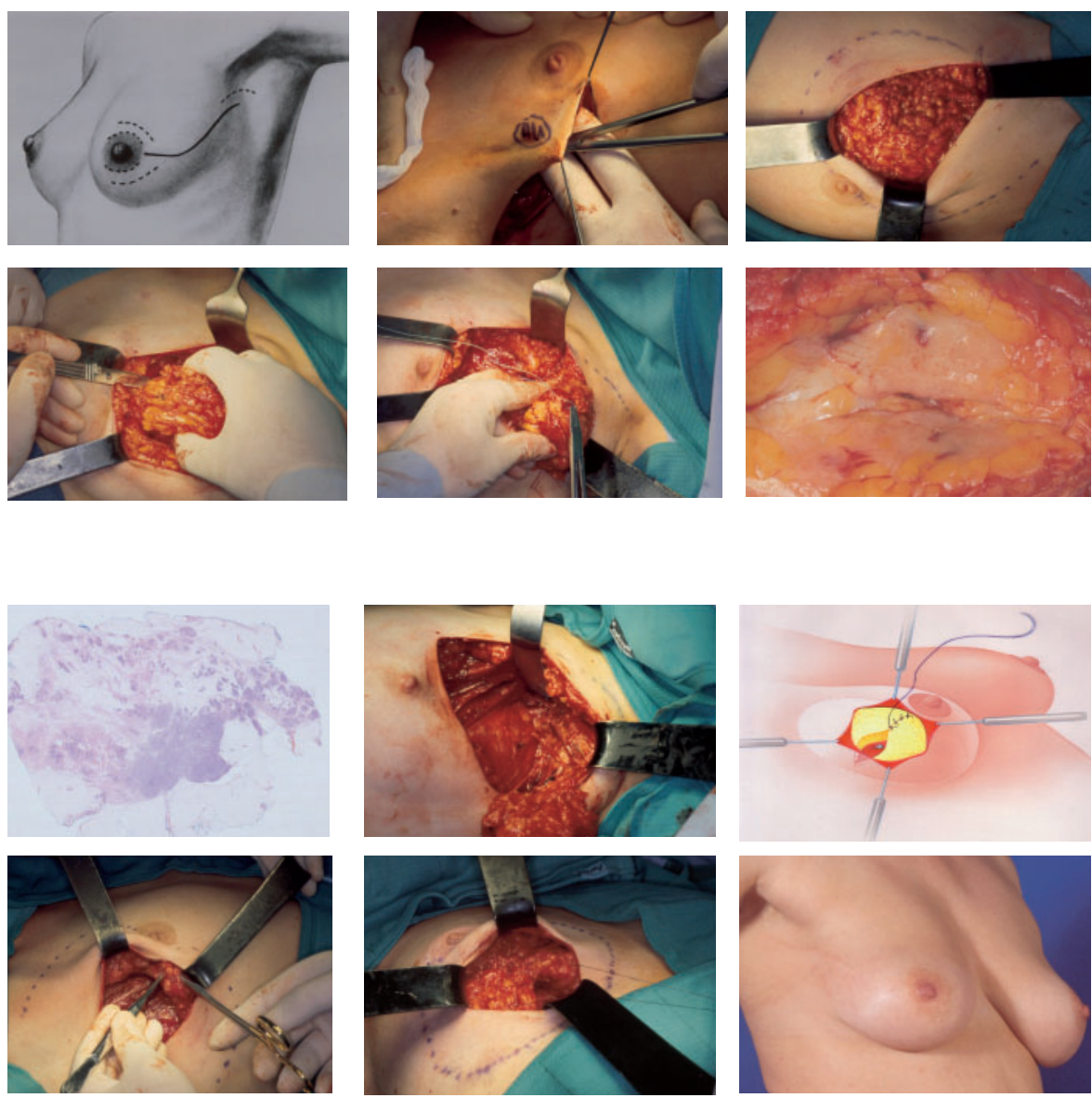

Fig. 2. Principle of partial mastector
struction with glandular rotation.
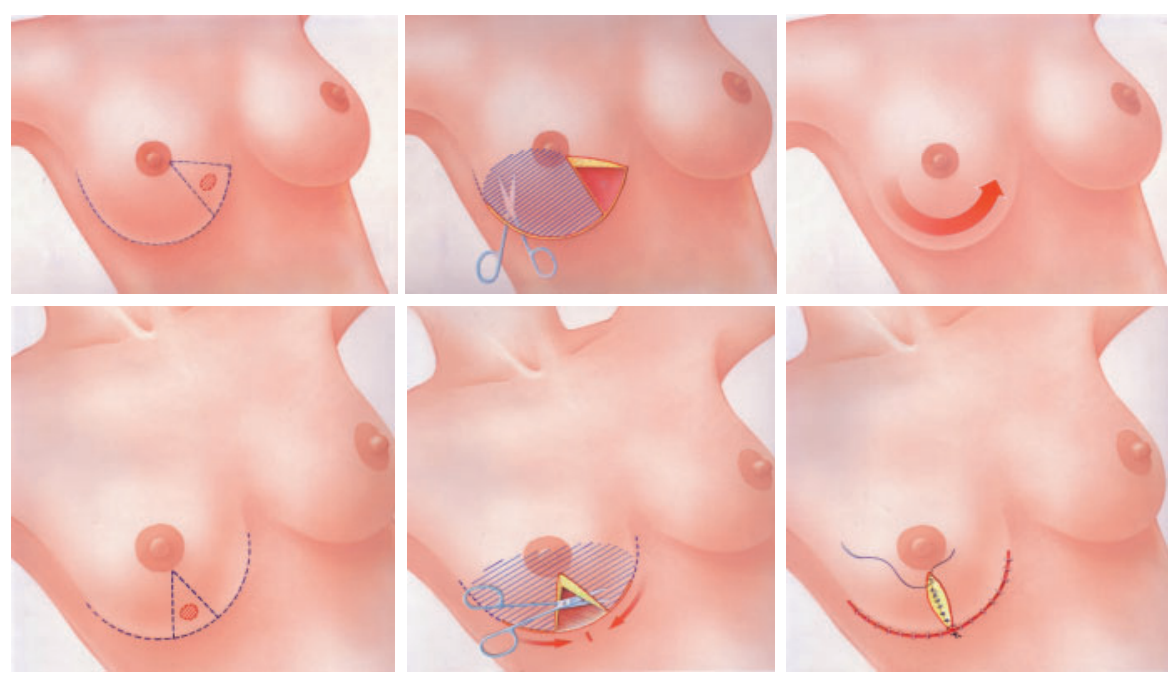

Fig. 3. a Dermoglandular rotation (tumoradapted mastopexy).

(Graphics kindly provided by Dr. M. Rezai, Düsseldorf)

and deformity. The use of oncoplastic techniques to prevent deformity can extend the scope of breast-conserving surgery, without compromising the adequacy of resection or the cosmetic outcome. Volume replacement can be used during and after previous breast-conserving surgery and radiotherapy to correct unacceptable deformity, and may prevent the need for mastectomy in some cases of local recurrence when further local excision will result in considerable volume loss.
The choice of technique depends on a number of factors, including the extent of resection, location of the tumor, timing of surgery, experience of the breast surgeon in oncoplastic techniques, and expectations of the patient. Partial mastectomy reconstruction at the same time as resection is gaining popularity. As a general rule, it is much easier to prevent than to correct a deformity, as the sequelae of previous surgery do not have to be addressed [21, 22]. Immediate reconstruction at 


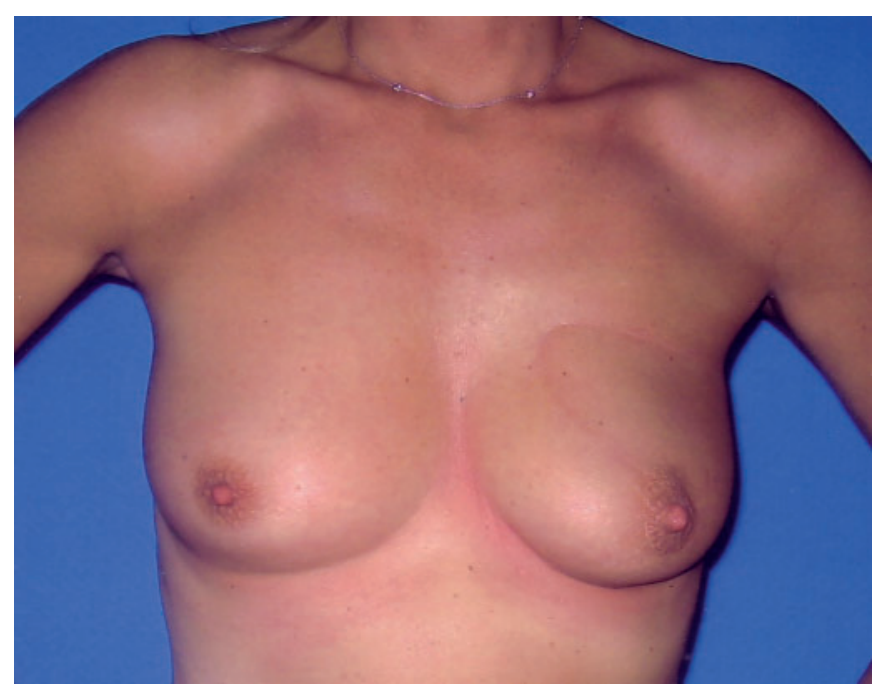

Fig. 3. b Dermoglandular rotation after partial mastectomy of the upper inner quadrant.

the time of partial mastectomy is associated with clear surgical, financial, and psychological benefits [23-25].

Resection defects can be reconstructed in 1 of 2 ways: i) by volume displacement with recruiting and transposing local glandular or dermoglandular flaps into the resection site, or ii) by volume replacement, importing volume from elsewhere to replace the amount of tissue resected (table 1). Volume replacement techniques can restore the shape and size of the breast, achieving symmetry and excellent cosmetic results without the need for contralateral surgery. However, these techniques require additional operation time and may be complicated by donor-site morbidity, flap loss, and an extended convalescence. In contrast, volume displacement techniques require less extensive surgery, limiting scars to the breast and avoiding donor-site problems.

\section{Volume Displacement Techniques}

Until recently, little attention has been paid to the cosmetic sequelae of breast-conserving surgery, as most patients are relieved not to lose their breast, and many gynecological and general breast surgeons are unfamiliar with the oncoplastic techniques that can eliminate postoperative deformities. Moreover, there has been a tendency to recommend delayed reconstructive surgery some time after completion of radiotherapy. Although this is possible, partial reconstruction of the breast after surgery and radiotherapy is technically challenging and requires sophisticated techniques, with cosmetic results that are often disappointing [22].

Poor remodeling is one of the reasons for an ugly deformity after breast-conserving surgery with partial mastectomy (lumpectomy, segmentectomy, or quadrantectomy). Although typical localized cancers of small size might be excised well by standard lumpectomy, segmentally extended cancers (invasive breast cancer with DCIS) need more creative approaches to surgical excision to remove breast tumors from nipple to periphery. This segmentectomy (fig. 1), as our standard procedure in breast-conserving surgery, is a full-thickness segmental resection extending from subdermal (Cooper's fascia) to the pectoralis major muscle including the pectoralis fascia. Partial mastectomy defects after segmentectomy can easily be reconstructed using the first standard principle of oncoplastic surgery - the glandular rotation.

\section{Glandular Rotation}

In cases of segmentectomy without skin resection, the glandular defect is easily approximated by mobilizing glandular flaps. For the standard segmentectomy, a cosmetically placed incision directly over the area to be removed is performed. For lesions especially in the upper breast, incisions are curvilinear following Langer's lines. The skin is undermined, sometimes extensively, liberating the whole quadrant from its skin attachment. In some cases, the central portion of the breast needs to be undermined, separating the nipple-areola complex from the underlying breast tissue. This allows transfer of some of the central volume of the breast towards the defect, making closure easier and preventing deviation of the nipple-areola complex towards the tumor bed. After clip-marking of the tumor bed, the 2 lateral glandular flaps are approximated and sutured into the defect. This approach can be used for most breast cancers in almost any location [16-18] (fig. 2).

Some surgeons perform no remodeling at all, leaving an empty defect and relying on a postoperative hematoma or seroma to fill the space. This may produce acceptable results in the short term but breast retraction invariably occurs with longer follow-up, leading to major deformities that are increased by postoperative radiotherapy [23]. On the other hand, hematoma or seroma filling leads to a worse inner cosmesis of the breast associated with diagnostic problems in mammography and sonography during follow-up.

\section{Tumor-Adapted Mastopexy}

In oncoplastic resections that include overlying skin because of skin involvement, or close relation of the breast cancer to skin less than $5 \mathrm{~mm}$, a wide spectrum of individually preferred oncoplastic techniques have been published which can be summarized as tumor-adapted mastopexies. These patients require preoperative planning and patient counseling, and it should not be decided in the operating room that the patient is a candidate for such an approach. The oncoplastic mastopexy techniques include the dermoglandular rotation for tumors in the upper or lower inner quadrant, the 'tennis racket' or Dufour coat technique with NAC recentralization for location in 
Fig. 4. Lateral thoracic wall advancement according to Rezai.

(Graphics kindly provided by Dr. M. Rezai, Düsseldorf)
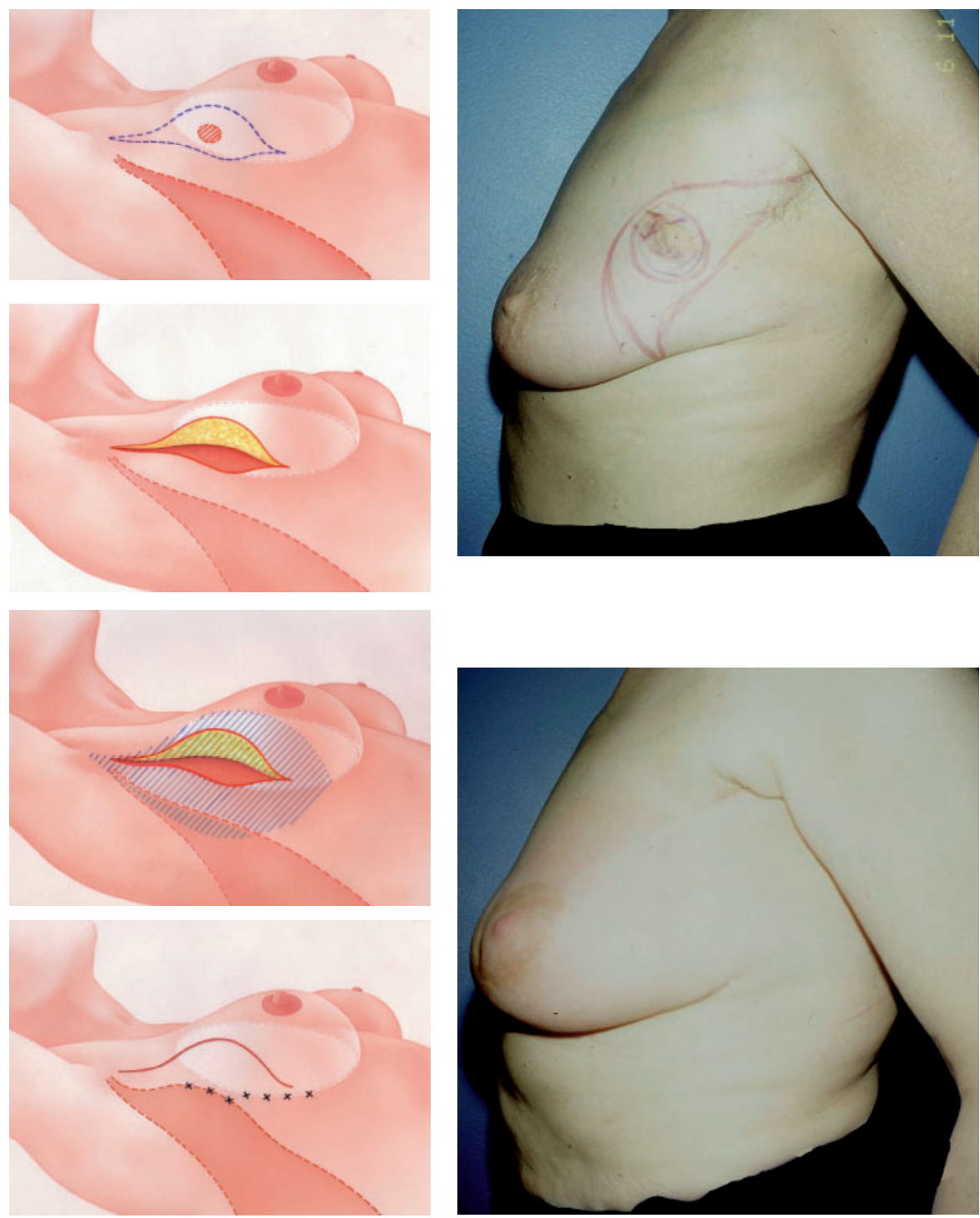

the upper outer quadrant, or the Regnault technique as a modified B-plasty for central, subareolar tumors. In our experience, we have only seen clear indications for the principle of dermoglandular rotation for tumors located in the upper or lower inner quadrant.

\section{Dermoglandular Rotation}

A limitation of full-thickness excision with the skin of the upper or lower inner breast quadrant is that it can cause upward or downward displacement of the nipple-areola complex, which results when too much skin is removed above or below the nipple. Skin resection is performed in a radial orientation. Grisotti defines the upper inner quadrant as a "no man's land'. A skin resection in this area followed by dermoglandular rotation will sometimes shift the nipple in an upward or medial fashion that would look highly unnatural in location. In such cases, the nipple-areola complex is always displaced towards the reference quadrant, and secondary repair of this deformity is difficult. The solution is to prevent this deformity by transferring the nipple-areola complex onto the center of the new breast dome at the time of primary surgery. Recentralization of the nipple-areola complex is performed by de-epithelializing a periareolar crescent of skin opposite the segmentectomy. The principle of dermoplandular rotation is shown in figure 3 .

\section{Tumor-Adapted Reduction Mammoplasty}

Another oncoplastic approach, when breast volume allows it (B cup or larger), is to perform a remodeling mammoplasty. The early use of mammoplasty techniques for breast-conserving surgery involved patients with large tumors located in the lower pole of the breast (superior pedicle mammoplasty). 

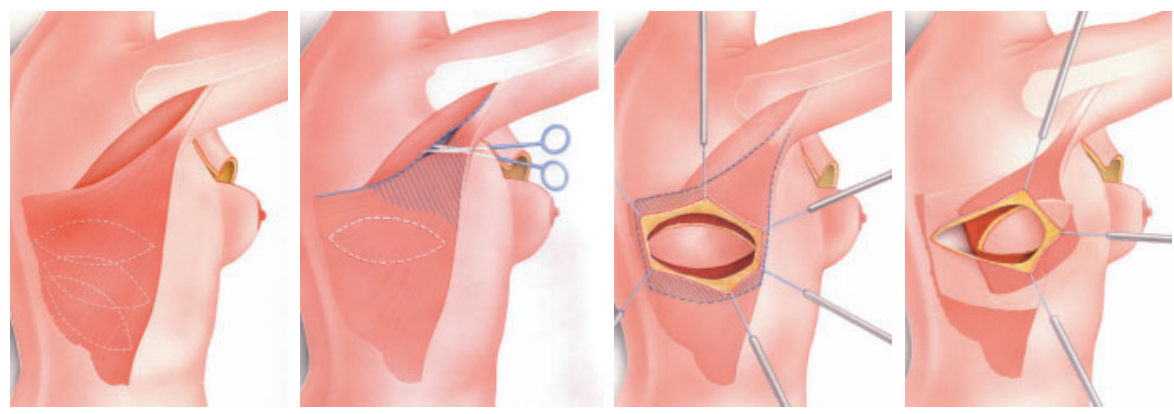

Fig. 5. Breast-conserving surgery with

latissimus dorsi flap.

(Graphics kindly provided by Dr. M. Rezai,

Düsseldorf)

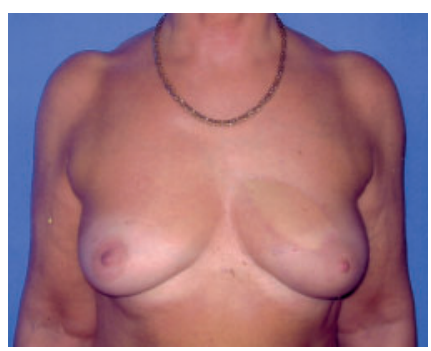

Lower-pole resections cause more deformity than resections in the upper quadrants, and these are impossible to prevent with the simple unilateral techniques just described. There are many advantages to this approach, but the main disadvantage is the need to achieve contralateral symmetry, which can be performed simultaneously in order to avoid secondary procedures.

There is a large spectrum of published techniques for mammoplasty with limitations in long-term aesthetic outcomes, scars and pedicles. Dr. Rezai developed a standardized and universal technique with an inferior flap to overcome the limitations of single mammoplasty techniques published in this issue. This principle method can be combined with inverted $\mathrm{T}$, vertical, and periareolar skin incisions, and is applicable for nearly all tumor locations (even the subareolar location) when glandular rotation or dermoglandular rotation is not applicable.

\section{Lateral Thoracic Wall Advancement}

For tumors located in the outer upper quadrant, the lateral thoracic wall advancement according to Rezai is an oncoplastic alternative to larger resection with dermoglandular rotations like 'tennis racket' or 'Dufour coat' technique [16] (fig. 4).

\section{Volume Replacement Techniques}

Several different approaches to volume replacement have been developed over the last 15 years, including myocutaneous, myosubcutaneous, and adipose flaps and implants [24-26]. Autologous latissimus dorsi flaps are the most popular options because of their versatility and reliability (fig. 5). The myocutaneous latissimus dorsi flap carries a skin paddle that can be used to replace skin which has been resected at the

time of breast-conserving surgery or as a result of contracture and scarring following previous resection and radiotherapy [27-32]. Although the skin paddle adds to the replacement volume, it can lead to a 'patch' effect because of the differences between the donor skin and the skin of the native breast. A myosubcutaneous latissimus dorsi flap circumvents this problem by harvesting the flap in a plane deep to Scarpa's fascia, or by de-epithelialization of the flap. This produces a bulky flap without a skin island to reconstruct defects following quadrantectomy, hemimastectomy, or skin-sparing mastectomy with preservation of the overlying skin.

Volume replacement should always be considered when adequate local tumor excision leads to an unacceptable degree of local deformity in those patients who wish to avoid mastectomy or contralateral surgery. This can occur after loss of $20 \%$ or more of the breast volume, particularly when the resection is performed from the central zone, lower pole, or medial quadrants of the breast. Breast conservation with or without reconstruction should be reserved for patients with unicentric tumors, and is inappropriate in those with more widespread disease or T4 tumors. Likewise, latissimus dorsi volume replacement is hazardous in patients with a history suggesting damage to the thoracodorsal pedicle. Patients should be informed that using the latissimus dorsi for breast conservation precludes its subsequent use for full breast reconstruction. If a mastectomy is required to treat recurrent disease, the options are limited to transverse rectus abdominis myocutaneous (TRAM) flaps or perforator flaps.

Donor-site seroma formation occurs in almost all patients, and can be reduced by quilting or delaying drain removal. Flap necrosis is rare, and can be avoided by gentle resection and handling of the pedicle and by taking care to prevent traction injuries during transposition and fixation of the flap after tendon division. Flap retraction can be avoided by division and fixation of the tendon and careful suture of the flap into the 
Fig. 6. Breast-conserving surgery with thoracoepigastric flap.

(Graphics kindly provided by Dr. M. Rezai, Düsseldorf)
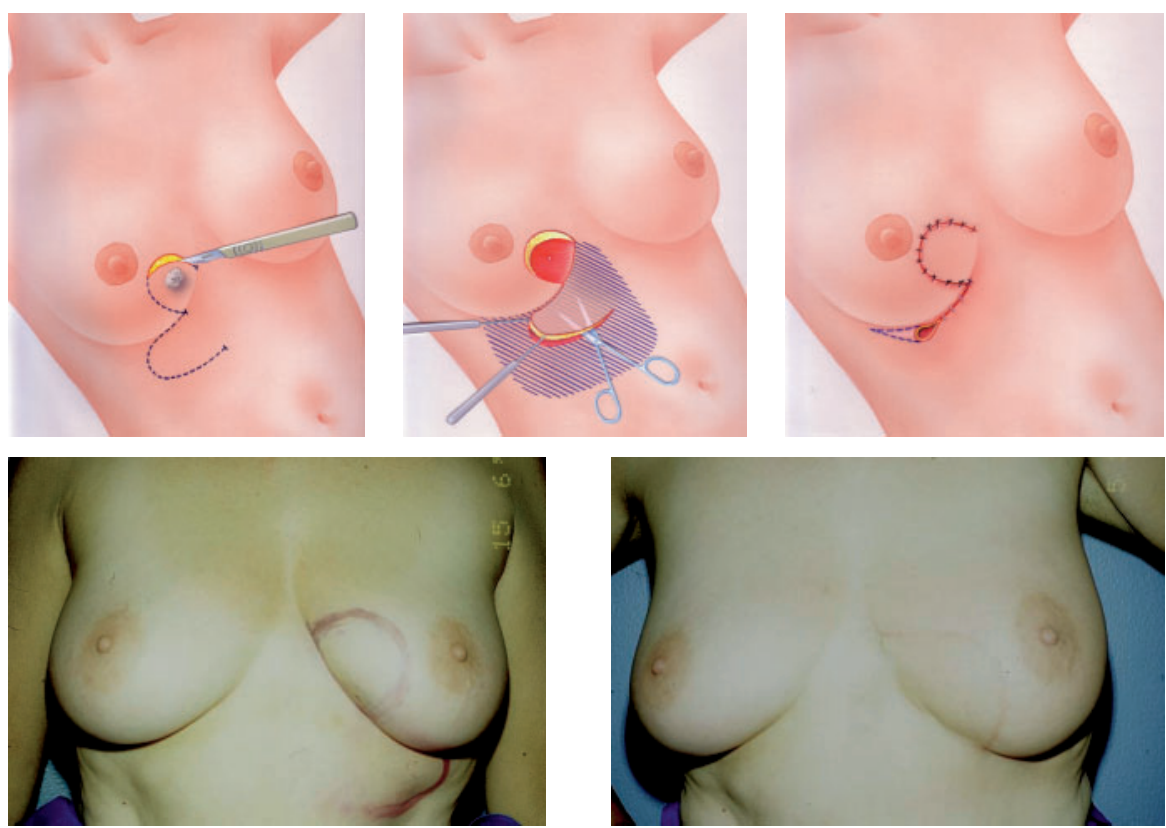

resection defect. Finally, volume replacement can preserve symmetry, and avoids the need for alterations to the contralateral breast in almost all patients.

The role of breast-conserving volume replacement is set to increase as more precise, image-guided resection of specific zones of breast tissue becomes possible. Increasingly sophisticated imaging techniques, such as high-frequency ultrasound and contrast-enhanced dynamic MRI, may in future enable exact delineation and excision of all malignant and premalignant changes. Endoscopically assisted techniques may increase the ability to harvest more bulky myosubcutaneous flaps, allowing the reconstruction of more extensive resection defects [33, 34]. This will require the further development of novel techniques for endoscopic dissection. Today, endoscopically assisted latissimus preparation is not the standard of care.

\section{Thoracoepigastric Flap}

For patients with breast cancer located in the lower inner quadrant with a need for a larger skin resection, a small thoracoepigatric flap can be used to reconstruct the resection defect adequately. In most patients, a dermoglandular rotation as volume displacement method will be the alternative for the breast-conserving treatment of tumors in this location [16] (fig. 6).

A number of factors need to be considered when making the choice between volume replacement and volume displacement. Volume replacement is particularly suitable for patients who wish to avoid volume loss and contralateral surgery after breast-conserving surgery. They must be prepared to accept a donor-site scar and be made aware of the possibility of major complications that may result in prolonged convalescence. Volume replacement is equally well suited to immediate and delayed reconstruction, and is the method of choice for correcting severe defects after quadrantectomy or hemimastectomy and type II deformity after previous breast irradiation.

\section{Secondary Reconstruction of the Partial Mastectomy Defect}

If volume displacement or volume replacement techniques are not used primarily in oncoplastic breast-conserving surgery, postoperative and postradiation deformities can be reconstructed. In order to better assess the surgical approach for these patients, a classification of the cosmetic sequelae after breast-conserving therapy has been published [14, 22]. This defined 3 groups of patients based on clinical examination. The advantage of this classification is that it is a valuable guide for choosing the optimal reconstructive technique, but it is also a good predictor of the final cosmetic result after surgery: i) Type I deformities: patients have a treated breast with a normal appearance but there is asymmetry between the two breasts; ii) Type II deformities: patients have a deformity of the treated breast, which can be corrected by partial breast reconstruction and breast conservation, with the irradiated breast tissue being spared in the reconstruction; iii) Type III deformities: patients have a major distortion of the treated breast, or diffuse painful fibrosis. These sequelae are so severe that only mastectomy can be considered.

For type I deformities, a contralateral mammoplasty is performed to restore symmetry, avoiding any surgery on the irradiated breast. This is a simple and reliable approach, the irradiated breast serving as the model for a contralateral breast 
lift or breast reduction. Type II deformities are almost always postoperative and are the most difficult to treat. A wide range of techniques can be used to repair these defects, from recentralization of the nipple to the insetting of a flap to reconstruct a missing quadrant. Type III deformities require treatment by mastectomy and immediate reconstruction with a myocutaneous flap.

\section{Conclusion}

Immediate reconstruction of a partial mastectomy defect extends the role of breast-conserving surgery by enabling complete excision of a greater range of tumors without compromising cosmesis, postoperative surveillance, or symmetry. Oncoplastic surgery with a critical use of standardized and classified volume displacement and replacement techniques is likely to become increasingly popular as an alternative to mastectomy in patients with small breast/tumor ratios. Further experience and training of the general breast surgeon in these techniques will lead to a better understanding of their role in the surgical management of primary breast cancer, and in the management of local relapse and cosmetic deformity after previous breast-conserving procedures. The specialized oncoplastic breast surgeon (gynecologist) needs to have a complete understanding and training in all aspects of breast cancer diagnosis (imaging, pathology) and treatment (locoregional and systemic) to choose the right technique for the right patient [35]. The indication and performance of a special oncoplastic technique should not be based on the personal preference of the breast surgeon. The achievement of as many aims and quality indicators of breast-conserving treatment as possible and the preferences of the patient after informed consent should determine which oncoplastic technique to use.

\section{References}

1 Halsted WS: The results of radical operations for the cure of carcinoma of the breast. Ann Surg 1907; 66:1.

2 Veronesi U, Cascinelli N, Mariani L: Twenty-year follow-up of a randomized study comparing breastconserving surgery with radical mastectomy for early breast cancer. N Engl J Med 2002;347: $1227-1232$.

3 Fisher B, Anderson S, Bryant J: Twenty-year follow-up of a randomized trial comparing total mastectomy, lumpectomy, and lumpectomy plus irradiation for the treatment of invasive breast cancer. $\mathrm{N}$ Engl J Med 2002;347:1233-1241.

4 Beckmann MW, Fasching RA, Gall C, Bani M, Brumm C, Krämer S: Genetic risk factors in breast cancer. Gynäkologe 2002;35:527-536.

5 Beckmann MW, Bani MR, Fasching PA, Strick R, Lux MP: Risk and risk assessment for breast cancer: molecular and clinical aspects. Maturitas 2007; 57:56-60.

6 Fisher B, Anderson S, Redmond CK: Reanalysis and results after 12 years of follow-up in a randomized clinical trial comparing total mastectomy with lumpectomy with or without irradiation in the treatment of breast cancer. N Engl J Med 1995;333: 1456-1461.

7 Solin LJ, Kurtz J, Forquet A: Fifteen-year results of breast-conserving surgery and definitive breast irradiation for the treatment of ductal carcinoma in situ of the breast. J Clin Oncol 196;14:754-763.

8 Veronesi U, Volterrani F, Luini A: Quadrantectomy versus lumpectomy for small size breast cancer. Eur J Cancer 1990;26:671-673.

9 Veronesi U, Saccozzi R, Del Vecchio M: Comparing radical mastectomy with quadrantectomy, axillary dissection and radiotherapy in patients with small cancers of the breast. N Engl J Med 1981:305: 6-11

10 Holland R, Connolly J, Gelman R: Histologic multifocality of Tis, T1-2 breast carcinomas: implications for clinical trials of breast-conserving treatment. Cancer 1985:56:979.
1 Krämer S, Schulz-Wendtland R, Hagedorn K, Bautz W, Lang N: Magnetic resonance imaging and its role in the diagnosis of multicentric breast cancer. Anticancer Res 1998;18:2163-2164.

12 Fisher B, Brown A, Mamounas E: Effect of preoperative chemotherapy on local-regional disease in women with operable breast cancer: findings from National Surgical Adjuvant Breast and Bowel Project B-18. J Clin Oncol 1997;15:2483-2493.

13 Bonadonna G, Veronesi U, Branbilla C: Primary chemotherapy to avoid mastectomy in tumors with diameters of three centimetres or more. J Natl Cancer Inst 1990;82:1539-1545.

14 Clough KB, Cuminet J, Fitoussi A: Cosmetic sequelae after conservative treatment for breast cancer: classification and results of surgical correction. Ann Plast Surg 1998;41:471-481.

15 Audretsch W, Rezai M, Kolotas C: Tumor-specific immediate reconstruction in breast cancer patients. Persp Plast Chir 1998;11:71-100.

16 Rezai M, Nestle-Krämling C: Onkoplastische Operationstechniken bei der brusterhaltenden Therapie des Mammakarzinoms. Gynäkologe 1999;32: 83-90.

17 Krämer S, Jäger W, Lang N, Beckmann MW: Operative Therapie des Mammakarzinoms. J Menopause 2004:11:9-15.

18 Dieterich H, Heyl V, SchelerP, Blazek J, Hoffmann G, Nestle-Krämling C: Rekonstruktion der Brust mit Eigengewebe. Gynäkologe 2005;38:217-229.

19 Clough KB, Kroll S, Audretsch W: An approach to the repair of partial mastectomy defects. Plast Reconstr Surg 1999;104:409-420.

20 Audretsch W, Andree C: Is mastectomy still justified - and if, in which patients ? Onkologie 2006;29: 243-245.

21 Clough K, Lewis JS, Couturaud B, Fitoussi A, Nos C, Falcout MC: Oncoplastic techniques allow extensive resections for breast-conserving therapy of breast carcinomas. Ann Surg 2003;237:26-34.
22 Slavin SA, Love SM, Sadowsky NL: Reconstruction of the irradiated partial mastectomy defect with autogenous tissues. Plast Reconstr Surg 1992; 90:854-865.

23 Kurtz JM: Impact of radiotherapy on breast cosmesis. Breast 1995;4:163-169.

24 Kroll SS, Singletary SE: Repair of partial mastectomy defects. Clin Plast Surg 1998;25:303-310.

25 Dean C, Chetty U, Forrest APM: Effect of immediate breast reconstruction on psychosocial morbidity after mastectomy. Lancet 1983;i:459-462.

26 Raja MAK, Straker VF, Rainsbury RM: Extending the role of breast-conserving surgery by immediate volume replacement. Br J Surg 1997;84:101-105.

27 Olivari N: The latissimus flap. Br J Plast Surg 1976; 29:126-128.

28 Dieterich H, Schwab R: Latissimus-dorsi-Hautmuskellappen. Die innovative Operationstechnik der Mammachirurgie. Gynäkologe 1999;32:91-97.

29 Rainsbury RM: Breast-sparing reconstruction with latissimus dorsi miniflaps. Eur J Surg Oncol 2002; 28:891-895.

30 Dixon JM, Venizelos B, Chan P: Latissimus dorsi mini-flap: a technique for extending breast conservation. Breast 2002;11:58-65.

31 Noguchi M, Taniya T, Miyasaki I: Immediate transposition of a latissimus dorsi muscle for correcting a post quadrantectomy breast deformity in Japanese patients. Int Surg 1990;75:166-170.

32 Aitken M, Mustoe TM. Why change a good thing ? The fleur de lis latissimus breast reconstruction. Plast Reconstr Surg 2002;109:525.

33 Van Buskark ER, Krehnke RD, Montgomery RL: Endoscopic harvest of the latissimus dorsi muscle using balloon dissection technique. Plast Reconstr Surg 1997;99:899-903.

34 Fine NA, Orgill DP, Pribaz JJ: Early clinical experience in endoscopic-assisted muscle flap harvest. Ann Plast Surg 1994;33:456.

35 Rutgers EJT for the EUSOMA Consensus Group: Quality control in the locoregional treatment of breast cancer. Eur J Cancer 37:447-453. 